\title{
Treating tobacco dependence in older adults: a survey of primary care clinicians' knowledge, attitudes, and practice
}

\author{
Lisa Huddlestone ${ }^{1 *}$, Gemma Michelle Walker ${ }^{2}$, Robana Hussain-Mills ${ }^{3}$ and Elena Ratschen ${ }^{1}$
}

\begin{abstract}
Background: The benefits of smoking cessation among older people are well documented. Despite this, evidence suggests that older smokers are rarely engaged in smoking cessation efforts, and that existing tobacco dependence treatments require further tailoring to the specific needs of older smokers. This study assesses the knowledge, attitudes, and clinical practice of primary care clinicians in relation to addressing tobacco dependence among older people.

Methods: A cross-sectional survey of 427 NHS primary care clinicians in a large English city was conducted using modified version of a previously validated questionnaire.

Results: One hundred and seventy one clinicians ( $40 \%$ response rate) completed the survey. While the majority (90.0 \%) of respondents reported enquiring regularly about older patients' smoking status, just over half (59.1\%) reported providing older patients with smoking cessation support. A lack of awareness in relation to the prevalence and impact of smoking in later life were apparent: e.g. only $47 \%$ of respondents were aware of that approximately 10 life years are lost due to smoking related disease, and only $59 \%$ knew that smoking can reduce the effectiveness of medication prescribed for conditions common in later life. Self-reported attendance at smoking-related training was significantly associated with proactive clinical practice.
\end{abstract}

Conclusions: There is a need to improve clinicians' knowledge, in relation to smoking and smoking cessation in older patients and to build clinician confidence in seizing teachable moments.

\section{Background}

While smoking prevalence among adults over 65 is lower $(\sim 10 \%)$ than that of the younger population [1], the consequences of smoking later in life is substantial [2-6]. The smoking habits and quit motivations of older adults have been shown to differ substantially from those of younger smokers, being intrinsically connected to specific life experiences, strongly mediated by the idiosyncratic socio-cultural context in which they live [7-9]. Despite this, older smokers have been shown to be more likely to want to make a quit attempt, less likely to relapse than younger people, and to experience significant health benefits following cessation $[10,11]$.

\footnotetext{
* Correspondence: Lisa.Huddlestone@nottingham.ac.uk

${ }^{1}$ Division of Epidemiology \& Public Health, The University Of Nottingham, Clinical Sciences Building, City Hospital Campus, Nottingham NG5 1PB, UK Full list of author information is available at the end of the article
}

With older people accounting for the highest activity and spend generated across primary care in England, having more regular and frequent contacts than the younger population [11], greater opportunities for the delivery of smoking cessation advice and treatment as recommended by the National Institute of Clinical Excellence (NICE) [12] exist. Despite this, and the proven effectiveness of smoking cessation treatment in older adults [13], many health professionals often fail to address tobacco dependence in older people $[11,14]$.

To our knowledge, no research has been conducted to explore issues relating to smoking and its treatment among older people in the context of primary care in England. This study explores primary care clinicians' knowledge and attitudes in relation to tobacco use and its treatment among older people, as well as the clinical practices of identifying, advising, and treating older smokers in England. 


\section{Methods}

\section{Participants and setting}

All $(n=427)$ health professionals working within 58 General practices (GP) and four specialist nursing teams (a Specialist Diabetes Nursing Service; a Community Matron Service; an Integrated Respiratory Service; and a Primary Care Cardiac Service) in a large city in the United Kingdom (UK) were invited to participate in the survey. Since 2013, all GP practices in England are accountable to local Clinical Commissioning Groups (CCGs), which also commission other health services, such as urgent and emergency care, elective hospital care, and rehabilitation services. Potential participants received an invitation to complete an online survey via email. While not incentivised, survey completion was encouraged by email cascade from practice and service managers two weeks after the initial invitation. Owing to a moderate uptake of the on-line survey, a paper version including return envelope was made available to all clinicians at their workplace, and was distributed with the assistance of a CCG Service Manager. Informed consent was obtained from all participants.

\section{Study instrument}

The survey (Additional file 1) was developed from an instrument used in a previous study [15] and the findings of published research [3-6, 10, 16]. Twenty-nine closed and multiple choice questions, including Likert scales explored primary care professionals' knowledge, attitudes, and current clinical practice related to tobacco dependence and its treatment among older people; additional questions related to reasons for not providing smoking cessation advice or treatment. An assessment of participants' knowledge was made by asking respondents to select the correct answer from a choice of five possible answers to questions relating to the prevalence of smoking within both the general population in England, the prevalence of smoking in people over 65 years, and the number of life years lost to smoking related disease; an option of "don't know" was included. Clinicians were asked to indicate their response of "correct" to a series of eight statements related to the impacts of smoking and quitting smoking in later life. Each of the statements provided was based upon the findings of previously published research [3-6, 10, 16]. Four false options (e.g. older people are less likely to want to quit smoking than younger smokers) were included.

Clinician attitudes towards addressing tobacco dependence among their older patients were assessed by asking respondents to rate their agreement with a series of statements on a 5-point Likert scale (strongly agree to strongly disagree). An exploration of clinician's professional practice relating to the identification and treatment of older smokers was carried out using six questions which focused on self-reported practice in the previous month (e.g. How often did you provide older smokers with brief advice or encouragement to consider stopping smoking?). Respondents were asked to indicate from four options (always, often, rarely, or never) how often they undertook the six activities. Those clinicians who responded "rarely" or "never" were asked to provide additional information as to the reason for their selection from multiple choice options (e.g. 'A number of the older people I have contact with have a terminal illness and I do not feel it would be appropriate to broach the subject of stopping smoking in these circumstances'.)

\section{Procedures}

Responses were coded and entered in to IBM SPSS (version 22) and missing data from respondents were coded as such. Staff groups were categorised into "medical" (GPs, GP trainees, consultant physicians, and junior doctors) and "non-medical" (practice nurses, nurse prescribers, specialist nurses, community nurses, and healthcare assistants (HCA's)). Where significant differences were detected between these groups, the nonmedical staff group was sub-divided into qualified nonmedical staff (nurses), and non-qualified non-medical staff (healthcare assistants) for more detailed analysis. Other a priori categories for analysis were based upon reported smoking status (current smoker v's nonsmoker), age range, gender, and reported attendance at training related to smoking.

In relation to participant knowledge of prevalence and the impact of smoking in later life on life years lost, responses were coded as correct or incorrect. To assess clinician knowledge in relation to the impact of smoking in older age, responses were coded and scored $(1=$ correct and $0=$ incorrect) and an overall median score with the percentage correct answers was calculated from a maximum of 8. Attitudinal Likert scale responses were dichotomised for analysis, with "strongly agree" and "agree" forming one category and "neither agree nor disagree", "disagree", or "strongly disagree" forming the other. Responses to statements relating to professional practice were scored according to the procedure described by Kerr and colleagues [17] and an overall score was calculated from a maximum score of 18 points; responses to the statements relating to professional practice were dichotomised with "always" and "often" forming one category and "rarely" or "never" forming the second category.

\section{Data analysis}

Means, medians, standard deviations, and proportions were obtained using descriptive analysis. Categorical data were analysed using Chi-squared tests to detect differences in outcome between the sub-groups; one-way ANOVA was used for continuous data; and logistic 
regression analysis was employed where statistical significance was indicated between subgroups to adjust for various significant factors; results are reported with odds ratios (OR) and $95 \%$ confidence intervals $(95 \% \mathrm{CI})$. Statistical significance was taken to be $p=0.05$.

\section{Ethical approval}

Favourable ethical opinion was obtained from the University of Nottingham Faculty of Medicine and Health Sciences Research Ethics Committee (H13032014 SoM EPH 14026) and NHS research governance approval was granted by the local Clinical Commissioning Group (CCG) and the commissioned community health provider.

\section{Results}

One hundred and seventy one clinicians responded to the survey (response rate $=40 \%$ ); 91 (21.3\%) completed the survey online and $80(18.7 \%)$ responded to the paper version.

\section{Participant characteristics}

Responses were received from 83 (48.5\%) medical staff, 74 (43.3 \%) qualified non-medical staff, 14 (8.2 \%) nonqualified, non-medical staff. Over three quarters $(76.6 \%)$ of respondents were female; the overall median age range was 50-59 years; and 11 (6.4\%) respondents identified themselves as current smokers. Nearly two thirds $(62.4 \%)$ reported receiving smoking related training; $70.2 \%$ of nurses reported training attendance compared to $58.5 \%$ of physicians and $42.8 \%$ of HCA's. Further details of respondent characteristics can be found in Table 1. Differences in responses were not associated with gender, smoking status, or age range.

\section{Knowledge of tobacco dependence and its treatment in older people}

Significant differences were found between the knowledge of medical staff and non-medical staff. Table 2 provides details of the respondent knowledge of smoking, smoking cessation, and the impact of smoking and quitting in older age.

The median number of correct answers provided by respondents was 6 out of a maximum of 8 (75.0\%). Doctors achieved a mean score of 6.7 (SD 0.9); nurses a mean score of 5.8 (SD 1.4); and HCA's a mean score of 4.7 (SD 1.1). Attendance at smoking related training was not found to be significantly associated with clinician knowledge of tobacco dependence and its treatment.

\section{Clinician attitudes regarding tobacco dependence treatment among older people}

Overall, clinicians reported positive attitudes towards addressing tobacco dependence among older patients. However, in relation to perceptions of knowledge and
Table 1 Characteristics of survey respondents

\begin{tabular}{lll}
\hline Respondent characteristic & $n=(\%)$ \\
\hline Gender & Male & $40(23.4)$ \\
Professional Role & Female & $131(76.6)$ \\
& GP & $73(42.7)$ \\
& Consultant Physician & $4(2.3)$ \\
& Junior Doctor & $2(1.2)$ \\
& Trainee GP & $4(2.4)$ \\
& Nurse Practitioner/Practice & $55(32.2)$ \\
& Nurse & \\
& Community Nurse/Specialist & $19(11.1)$ \\
Nurse & $14(8.2)$ \\
Age Range & Healthcare Assistant & $7(4.1)$ \\
& 20-29 years & $39(22.8)$ \\
30-39 years & $55(32.2)$ \\
smoking related & 40-49 years & $61(35.7)$ \\
training & 50-59 years & $9(5.3)$ \\
\hline 60-69 years & $11(6.4)$ \\
& Current smoker & $160(93.6)$ \\
& Non-smoker & $106(62.4)$ \\
& & $64(37.6)$ \\
\hline
\end{tabular}

skills in relation to identifying and treating tobacco dependence significantly more medical staff reported having this capacity than their non-medical colleagues.

Training attendance was found to be significantly associated with one attitudinal statement. Respondents who reported having attended training, were significantly less likely to hold the belief that "smoking is one of the few pleasures older people have" than those who had not attended training (81.0 \% vs $67.2 \%, p=0.043)$. Table 3 shows the frequency of clinician attitudes towards addressing tobacco dependence among older patients by professional group and attendance at training on the attitudes of clinicians with regard to tobacco dependence and its treatment in older people.

\section{Clinical practice with older smokers}

Table 4 presents the frequency of respondents' clinical practice relating to identifying and addressing tobacco dependence among older patients, by professional group and attendance at smoking related training. When compared to non-medical staff, medical staff were found to be significantly more likely to report regular proactive clinical practice in relation to addressing tobacco dependence among older people. However, when the nonmedical staff group was sub-divided to allow for an exploration of differences, in comparison to healthcare 
Table 2 Respondent knowledge of smoking, smoking cessation and the impact of smoking and smoking cessation in older age

\begin{tabular}{|c|c|c|c|c|c|c|c|c|c|c|}
\hline \multirow[t]{2}{*}{ Statement } & & \multirow{2}{*}{$\begin{array}{l}\text { All responses } \\
n=(\%)\end{array}$} & \multicolumn{4}{|c|}{ Professional Group [n=(\%)] } & \multicolumn{4}{|c|}{ Training Attendance $[n=(\%)]$} \\
\hline & & & Medical & Non-medical & Statistic $X^{2}(\mathrm{df}=1)$ & Sig $p=$ & Training & No Training & Statistic $X^{2}(\mathrm{df}=1)$ & $\operatorname{Sig} p=$ \\
\hline \multirow{2}{*}{$\begin{array}{l}\text { Approximately } 20 \% \text { of the } \\
\text { UK adult population smokes. } \\
\text { (True) }\end{array}$} & Correct & $79(46.1)$ & $43(54.4)$ & $36(39.1)$ & 4.00 & 0.048 & $48(45.3)$ & $31(48.4)$ & 0.16 & 0.752 \\
\hline & Incorrect & $92(53.9)$ & 36 (45.6) & $56(60.9)$ & & & $58(54.7)$ & $33(51.6)$ & & \\
\hline \multirow{2}{*}{$\begin{array}{l}\text { Approximately } 10 \% \text { of adults } \\
\text { over the age of } 65 \text { smokes. } \\
\text { (True) }\end{array}$} & Correct & $23(13.5)$ & $10(12.7)$ & $13(14.1)$ & 0.07 & 0.825 & $11(10.4)$ & $12(18.7)$ & 2.39 & 0.164 \\
\hline & Incorrect & $148(86.5)$ & $69(87.3)$ & 79 (85.9) & & & 95 (89.6) & $52(81.3$ & & \\
\hline \multirow{2}{*}{$\begin{array}{l}\text { Approximately } 10 \text { life years are } \\
\text { lost on average to smoking } \\
\text { related disease. (True) }\end{array}$} & Correct & $80(46.8)$ & $51(64.5)$ & $29(31.5)$ & 18.63 & $<0.001$ & $48(45.3)$ & $31(48.4)$ & 0.16 & 0.752 \\
\hline & Incorrect & $91(53.2)$ & $28(35.5)$ & $63(68.5)$ & & & $58(54.7)$ & $33(51.6)$ & & \\
\hline \multirow{2}{*}{$\begin{array}{l}\text { Smoking can reduce the effectiveness } \\
\text { of certain medications that are } \\
\text { prescribed for conditions which } \\
\text { are common in later life. (True) }\end{array}$} & Correct & $101(59.1)$ & $51(64.5)$ & $50(54.3)$ & 1.83 & 0.213 & $63(59.4)$ & $37(57.8)$ & 0.04 & 0.873 \\
\hline & Incorrect & $70(40.1)$ & $28(35.5)$ & $42(45.7)$ & & & $43(40.6)$ & $27(42.2)$ & & \\
\hline \multirow{2}{*}{$\begin{array}{l}\text { Smoking can delay wound healing } \\
\text { in older people. (True) }\end{array}$} & Correct & $153(89.4)$ & $73(92.4)$ & $80(86.6)$ & 1.34 & 0.320 & 94 (88.7) & 58 (90.6) & 0.16 & 0.800 \\
\hline & Incorrect & 18 (10.6) & $6(7.6)$ & $12(13.4)$ & & & $12(11.3)$ & $6(9.4)$ & & \\
\hline \multirow{2}{*}{$\begin{array}{l}\text { The risk of an older person having } \\
\text { a heart attack or stroke increases } \\
\text { within } 24 \mathrm{~h} \text { of stopping smoking. } \\
\text { (False) }\end{array}$} & Correct & $148(86.5)$ & $73(92.4)$ & 75 (81.5) & 4.33 & 0.044 & $92(86.7)$ & 55 (85.9) & 0.02 & 1.000 \\
\hline & Incorrect & $23(13.5)$ & $6(7.6)$ & $17(18.5)$ & & & $14(13.3)$ & $9(14.1)$ & & \\
\hline \multirow{2}{*}{$\begin{array}{l}\text { Smoking can speed cognitive } \\
\text { decline in older people. (True) }\end{array}$} & Correct & $129(75.4)$ & 75 (94.9) & $54(58.7)$ & 30.13 & $<0.001$ & 77 (72.6) & 51 (79.7) & 1.06 & 0.361 \\
\hline & Incorrect & $42(24.6)$ & $4(5.1)$ & $38(41.3)$ & & & $29(27.4)$ & $13(20.3)$ & & \\
\hline \multirow{2}{*}{$\begin{array}{l}\text { Smoking does not generally stop the } \\
\text { progression of chronic obstructive } \\
\text { pulmonary disease (COPD). (False) }\end{array}$} & Correct & 135 (78.9) & 67 (84.8) & 68 (73.9) & 3.08 & 0.093 & 89 (83.9) & $45(70.3)$ & 4.45 & 0.052 \\
\hline & Incorrect & $36(21.1)$ & $12(15.2)$ & $24(26.1)$ & & & $17(16.1)$ & 19 (29.7) & & \\
\hline \multirow{2}{*}{$\begin{array}{l}\text { Smoking can cause serious } \\
\text { complications in older people } \\
\text { with diabetes. (True) }\end{array}$} & Correct & $162(94.7)$ & 78 (98.7) & 84 (91.3) & 4.71 & 0.030 & 99 (93.4) & $62(96.9)$ & 0.96 & 0.486 \\
\hline & Incorrect & $9(5.3)$ & $1(1.3)$ & $8(8.7)$ & & & $7(6.6)$ & $2(3.1)$ & & \\
\hline \multirow{2}{*}{$\begin{array}{l}\text { Older smokers are less likely to } \\
\text { want to quit smoking than } \\
\text { younger smokers. (False) }\end{array}$} & Correct & $93(54.4)$ & $51(64.5)$ & $42(45.6)$ & 6.12 & 0.014 & $62(58.5)$ & $31(48.4)$ & 1.63 & 0.202 \\
\hline & Incorrect & 78 (45.6) & 28 (35.5) & $50(54.4)$ & & & $44(41.5)$ & 33 (51.6) & & \\
\hline \multirow{2}{*}{$\begin{array}{l}\text { Brief smoking cessation advice is } \\
\text { less effective than more intensive } \\
\text { advice in helping older people to } \\
\text { stop smoking. (False) }\end{array}$} & Correct & $133(77.8)$ & $62(79.7)$ & 70 (76.1) & 0.33 & 0.586 & $84(79.2)$ & 49 (76.6) & 0.17 & 0.704 \\
\hline & Incorrect & $38(22.2)$ & $16(20.3)$ & $22(23.9)$ & & & $22(20.8)$ & 15 (23.4) & & \\
\hline
\end{tabular}


Table 3 Frequency of clinician attitudes towards addressing tobacco dependence among older patients

\begin{tabular}{|c|c|c|c|c|c|c|c|c|c|c|}
\hline \multirow[t]{2}{*}{ Statement } & & \multirow{2}{*}{$\begin{array}{l}\text { All responses } \\
n=(\%)\end{array}$} & \multicolumn{4}{|c|}{ Professional Group $n=(\%)$} & \multicolumn{4}{|c|}{ Training Attendance $n=(\%)$} \\
\hline & & & Medical & Non-medical & Statistic $X^{2}(d f=1)$ & Sig $p=$ & Training & No Training & Statistic $X^{2}(d f=1)$ & Sig $p=$ \\
\hline \multirow{2}{*}{$\begin{array}{l}\text { I feel it lies within my remit of responsibility } \\
\text { as a health professional to assist older } \\
\text { people who smoke to address their tobacco } \\
\text { dependence. }\end{array}$} & Agree & $154(90.0)$ & $75(94.9)$ & $79(85.9)$ & 3.9 & 0.071 & $98(92.4)$ & $55(85.9)$ & 1.9 & 0.193 \\
\hline & Disagree & $17(10.0)$ & $4(5.1)$ & $13(14.1)$ & & & $8(7.6)$ & $9(14.1)$ & & \\
\hline \multirow{2}{*}{$\begin{array}{l}\text { I feel I have sufficient knowledge of the } \\
\text { detrimental effects of smoking in later } \\
\text { life to be able to discuss this effectively } \\
\text { when I have contact with older patients } \\
\text { who smoke. }\end{array}$} & Agree & $134(78.9)$ & $69(87.3)$ & $65(70.6)$ & 6.9 & 0.009 & $86(81.1)$ & $47(73.4)$ & 1.4 & 0.255 \\
\hline & Disagree & $37(21.1)$ & $10(12.7)$ & $27(29.4)$ & & & $20(18.9)$ & $17(26.6)$ & & \\
\hline \multirow{2}{*}{$\begin{array}{l}\text { I feel I have sufficient knowledge } \\
\text { of the benefits of stopping smoking } \\
\text { in later life to be able to discuss this } \\
\text { effectively with older patients who } \\
\text { smoke. }\end{array}$} & Agree & $135(78.3)$ & $71(89.8)$ & $64(69.5)$ & 10.5 & 0.001 & $87(82.1)$ & $47(73.4)$ & 1.8 & 0.245 \\
\hline & Disagree & $36(21.7)$ & $8(10.2)$ & $28(30.5)$ & & & 19 (17.9) & 17 (26.6) & & \\
\hline \multirow{2}{*}{$\begin{array}{l}\text { I feel I have sufficient knowledge of } \\
\text { the barriers that may prevent older } \\
\text { people from attempting to stop } \\
\text { smoking. }\end{array}$} & Agree & 102 (59.6) & $48(60.7)$ & $54(58.7)$ & 0.1 & 0.876 & $69(65.1)$ & $32(50.0)$ & 3.8 & 0.056 \\
\hline & Disagree & $69(40.4)$ & 31 (39.3) & $38(41.3)$ & & & 37 (34.9) & $32(50.0)$ & & \\
\hline \multirow{2}{*}{$\begin{array}{l}\text { I feel I have sufficient knowledge } \\
\text { of nicotine addiction/withdrawal } \\
\text { to be able to discuss this effectively } \\
\text { with older patients who smoke. }\end{array}$} & Agree & $123(71.9)$ & $59(74.6)$ & 64 (70.6) & 0.5 & 0.498 & 81 (76.4) & $42(65.6)$ & 2.3 & 0.157 \\
\hline & Disagree & $48(28.1)$ & $20(25.4)$ & $28(29.4)$ & & & 25 (23.6) & $22(34.4)$ & & \\
\hline \multirow{2}{*}{$\begin{array}{l}\text { I feel I have the skills required to } \\
\text { be able to encourage older patients } \\
\text { who smoke to make a quit attempt. }\end{array}$} & Agree & $122(71.7)$ & $66(83.5)$ & $56(61.5)$ & 10.1 & 0.002 & 79 (75.2) & $42(65.6)$ & 1.8 & 0.219 \\
\hline & Disagree & 48 (28.3) & 13 (16.5) & 35 (38.5) & & & $26(24.8)$ & $22(34.4)$ & & \\
\hline \multirow{2}{*}{$\begin{array}{l}\text { I feel I have sufficient knowledge } \\
\text { of nicotine replacement and other } \\
\text { pharmacotherapies which can help } \\
\text { older smokers to quit, and feel able } \\
\text { to discuss this with patients. }\end{array}$} & Agree & $115(67.6)$ & $60(75.9)$ & $55(60.4)$ & 4.6 & 0.034 & 74 (70.4) & $41(64.1)$ & 0.7 & 0.400 \\
\hline & Disagree & $55(32.4)$ & $19(24.1)$ & 36 (39.6) & & & 31 (29.6) & $23(35.9)$ & & \\
\hline \multirow{2}{*}{$\begin{array}{l}\text { I am comfortable discussing my } \\
\text { older patients smoking behaviours } \\
\text { with them. }\end{array}$} & Agree & $136(80.4)$ & $72(92.3)$ & $64(70.3)$ & 12.9 & $<0.001$ & 87 (83.6) & 49 (76.5) & 1.3 & 0.312 \\
\hline & Disagree & 33 (19.6) & $6(7.7)$ & 27 (29.7) & & & $17(16.4)$ & 15 (23.5) & & \\
\hline \multirow{2}{*}{$\begin{array}{l}\text { Smoking is one of the few } \\
\text { pleasures older people have. }\end{array}$} & Agree & $41(24.1)$ & $7(8.9)$ & $34(37.4)$ & 18.7 & $<0.001$ & 20 (19.0) & 21 (32.8) & 4.1 & 0.043 \\
\hline & Disagree & $129(75.9)$ & 72 (91.9) & $57(62.6)$ & & & 85 (81.0) & $43(67.2)$ & & \\
\hline \multirow{2}{*}{$\begin{array}{l}\text { Giving up smoking is unlikely to } \\
\text { provide older people with any benefit. }\end{array}$} & Agree & $9(5.2)$ & $0(0.0)$ & $9(9.8)$ & 8.3 & 0.004 & $4(3.8)$ & $5(7.8)$ & 1.3 & 0.302 \\
\hline & Disagree & $161(94.8)$ & 79 (100.0) & $82(90.2)$ & & & $101(96.2)$ & 59 (92.2) & & \\
\hline \multirow{2}{*}{$\begin{array}{l}\text { I feel that it is the role of more } \\
\text { specialist staff to actually support } \\
\text { an older patient's cessation attempt. }\end{array}$} & Agree & $51(30.0)$ & $24(30.3)$ & 27 (29.7) & 0.10 & 1.000 & $26(24.7)$ & 25 (39.0) & 3.9 & 0.058 \\
\hline & Disagree & $119(70.0)$ & $55(69.7)$ & $64(70.3)$ & & & 79 (75.3) & 39 (61.0) & & \\
\hline
\end{tabular}


Table 4 Frequency of respondents' clinical practice to identify and address tobacco dependence among older patients

\begin{tabular}{|c|c|c|c|c|c|c|c|c|c|c|}
\hline \multirow{2}{*}{\multicolumn{2}{|c|}{ Statement }} & \multirow{2}{*}{$\begin{array}{l}\text { All } \\
\text { responses } \\
n=(\%)\end{array}$} & \multirow{2}{*}{\multicolumn{4}{|c|}{ Professional Group $[n=(\%)]$}} & \multicolumn{4}{|c|}{ Training Attendance $[n=(\%)]$} \\
\hline & & & & \multirow{2}{*}{$\begin{array}{l}\text { Non-medical } \\
78(84.8)\end{array}$} & & & & & & \\
\hline How often do you ask older & Always/often & $154(90.1)$ & $\begin{array}{l}\text { Medical } \\
76(96.2)\end{array}$ & & $\begin{array}{l}\text { Statistic } X^{2}(\mathrm{df}=1) \\
6.19\end{array}$ & $\begin{array}{l}\text { Sig } p= \\
0.019\end{array}$ & $\begin{array}{l}\text { Training } \\
98(92.5)\end{array}$ & $\begin{array}{l}\text { No Training } \\
55 \text { (85.9) }\end{array}$ & $\begin{array}{l}\text { Statistic } X^{2}(\mathrm{df}=1) \\
1.88\end{array}$ & $\begin{array}{l}\text { Sig } p= \\
0.170\end{array}$ \\
\hline $\begin{array}{l}\text { patients about thelr smoking } \\
\text { status? }\end{array}$ & Rarely/never & $17(9.9)$ & $3(3.8)$ & $14(15.2)$ & & & $8(7.5)$ & $9(14.1)$ & & \\
\hline \multirow{2}{*}{$\begin{array}{l}\text { How often did you document } \\
\text { an older smokers' smoking status } \\
\text { in their clinical records? }\end{array}$} & Always/often & $155(90.1)$ & $75(94.9)$ & $80(86.9)$ & 3.19 & 0.112 & $100(94.3)$ & $54(84.3)$ & 4.65 & 0.031 \\
\hline & Rarely/never & $16(9.9)$ & $4(5.1)$ & $12(13.1)$ & & & $6(5.7)$ & $10(15.7)$ & & \\
\hline \multirow{2}{*}{$\begin{array}{l}\text { How often did you assess older } \\
\text { smokers' motivation/readiness to } \\
\text { stop smoking? }\end{array}$} & Always/often & $130(75.9)$ & $65(82.3)$ & $65(70.7)$ & 3.15 & 0.105 & 89 (83.9) & $40(62.5)$ & 10.04 & 0.002 \\
\hline & Rarely/never & $41(24.1)$ & $14(17.7)$ & $27(29.3)$ & & & $17(16.1)$ & $24(37.5)$ & & \\
\hline \multirow{2}{*}{$\begin{array}{l}\text { How often did you provide older } \\
\text { smokers with brief advice or } \\
\text { encouragement to consider } \\
\text { stopping smoking? }\end{array}$} & Always/often & $133(77.8)$ & $67(84.8)$ & $66(71.7)$ & 4.20 & 0.040 & $86(81.1)$ & $46(71.8)$ & 1.97 & 0.185 \\
\hline & Rarely/never & $38(22.2)$ & $12(15.2)$ & $26(28.3)$ & & & $20(18.9)$ & $18(28.2)$ & & \\
\hline \multirow{2}{*}{$\begin{array}{l}\text { How often did you discuss the } \\
\text { benefits of stopping smoking with } \\
\text { the older smokers you have had } \\
\text { contact with? }\end{array}$} & Always/often & $123(71.9)$ & $63(79.7)$ & $60(65.2)$ & 4.44 & 0.041 & $84(79.2)$ & $38(59.4)$ & 7.78 & 0.008 \\
\hline & Rarely/never & $48(28.1)$ & $16(20.3)$ & $32(34.8)$ & & & $22(20.8)$ & $26(40.6)$ & & \\
\hline \multirow{2}{*}{$\begin{array}{l}\text { How often did you provide older } \\
\text { smokers with support (including } \\
\text { NRT or referral to local stop smoking } \\
\text { services) to make a quit attempt? }\end{array}$} & Always/often & $100(59.1)$ & $55(71.4)$ & $45(48.9)$ & 8.80 & 0.005 & $69(65.7)$ & 30 (47.6) & 5.33 & 0.024 \\
\hline & Rarely/never & 69 (40.9) & 22 (28.6) & $47(51.1)$ & & & 36 (34.3) & $33(52.4)$ & & \\
\hline
\end{tabular}


assistants, nurses were significantly more likely to: make enquiries as to older patients smoking status [90.5\% vs $64.2 \%$, OR 3.51 (95 \% CI 1.4-8.7), $p=0.021$ ]; record older patients smoking status $[93.2 \%$ vs $64.2 \%$, OR 4.33, (95 \% CI 1.8-10.3), $p=0.008$; assess older smokers motivation to stop smoking [79.7 \% vs $28.6 \%$, OR 6.30, (95\% CI 2.2-18.2), $p=<0.001$; provide older smokers with brief advice in relation to smoking [82.4 \% vs $21.4 \%$, OR 9.78, (95 \% CI 2.98-32.1), $p=<0.001$ ]; discuss the benefits of smoking cessation with older patients $[75.7 \%$ vs 7.1 \%, OR 23.9, (95 \% CI 3.3-174.2-), $p=<0.001$ ]; and supporting smoking cessation attempts including referral to stop smoking services [55.4 \% vs $21.4 \%$, OR 3.67, (95 \% CI $1.1-12.6), p=0.039$ ]. The overall median score summarising respondents' clinical practice relating to treating tobacco dependence among older smokers was 12 out of a maximum of 18 (2-18). Nurses achieved a mean score of 12.8 (SD 3.6), while doctors and HCA's obtained a mean score of 12.3 (SD 2.8) and 8.3 (SD 3.8) respectively.

Training was found to have a positive association with a number of the clinical practices assessed in this survey. Overall, those clinicians who had received smoking related training achieved a slightly higher mean score in relation to their practice of addressing smoking among older adults when compared to those who had not attended smoking related training [12.79 (SD 3.2) vs 11.13 (SD 3.6), respectively].

\section{Reported barriers to addressing tobacco dependence among older people in primary care}

Thirty-one participants (18.1\%) cited time constraints as a barrier to addressing tobacco use among older patients. While only $6.5 \%$ of clinicians stated that they did not believe it was part of their role to discuss smoking and smoking cessation with their older patients, significantly more non-medical staff were likely to adopt this view than medical staff $(10.9 \%$ vs $1.3 \%$, $p=0.012)$. Similarly, with less than five percent $(4.8 \%)$ of respondents believing it unfair to ask older people to quit, non-medical staff were found to be statistically more likely to believe this in contrast to medical staff ( $8.7 \%$ vs $0.0 \%, p=0.008)$. Only $3.5 \%(n=6)$ of respondents believed that raising the subject of smoking would damage the patient-clinician relationship and 40 (23.4\%) respondents believed that it was not appropriate to broach the subject of smoking with older patients due to conditions such as dementia, terminal illness, and mental disorders.

\section{Logistic regression analysis}

Professional group and training attendance variables shown to have a positive effect on attitudes and clinical practice at $p=0.05$ level, were entered into a logistic regression model. Training attendance by non-medical staff was found to increase the odds of disagreeing with the statement "smoking is one of the few pleasures older people have" by 2.1 times (95\% CI 1.1-4.2, $p=0.045$ ). Training increased the likelihood of respondents practice relating to discussing the benefits of smoking cessation with older patients by 2.3 times (95\% CI 1.1-4.9, $p=0.019$ ) among medical staff and by 2.9 times for non-medical staff (95\% CI 1.4-5.6, $p=0.003$ ). Finally, the odds of respondents providing older patients with smoking cessation support increased with training by 2.4 times for medical ( $95 \%$ CI 1.2-4.7, $p=0.009$ ) and by 3.0 times for non-medical staff (95\% CI 1.4-5.6, $p=0.002$ ).

\section{Discussion}

The findings of this study suggest that, while primary care clinicians have overall adopted proactive practices towards addressing tobacco dependence among older patients, opportunities to encourage and support cessation might be missed through lack of awareness of the impacts of smoking and the benefits of smoking cessation in later life specifically.

To our knowledge, this is the first survey to explore the treatment of tobacco dependence specifically relating to older adults among NHS primary care clinicians in England. While the response rate (40\%) of this study is a limitation, it is noteworthy that it compares favourably with response rates found in recent surveys conducted among primary care clinicians in the UK $[17,18]$. The generalizability of results may further be limited by survey-typical reporting bias; however, due to the inclusion of 58 general practices and 4 specialist community teams in a large and demographically diverse English city, we believe that this survey constitutes a valuable contribution to the literature. Furthermore the gender characteristics and smoking prevalence of participants comparable to that reported to exist among the primary care workforce; for example a study conducted by Drennan and colleagues [19] found a female predominance (96\%) among nurses and healthcare assistants working in general practice settings with a smoking prevalence of $5 \%$, while smoking among GP's has been reported to be $4 \%$ [20]. While the number of healthcare assistants who completed the survey is lower in comparison to other staff groups, compares favourably with the reported $9.3 \%$ of healthcare assistants working within primary care [21].

Considerable inconsistency was identified between clinician staff groups in their knowledge of tobacco dependence and its treatment in older adults. If tobacco use among older people is to be effectively addressed, knowledge in relation to its prevalence, impacts, and treatment is essential. However, in this survey the majority of respondents believed smoking prevalence within the general and elderly populations to be in excess of 
published statistics, and few reported an awareness of the number of life years lost to smoking related disease. Despite medical staff showing a greater awareness of the impact of smoking and smoking cessation specific to older people, gaps in knowledge were present across all staff groups. A lack of awareness relating to the interaction between smoking and medications used to treat conditions in old age is of particular clinical importance, since it may result in ineffective prescribing or in an exacerbation of chronic conditions: smoking can affect mean serum levels for drugs such as propranolol and theophylline, and is widely reported to decrease levels of anti-depressants, anti-psychotic, and opiate based medication; additionally, heavy smokers require one and a half times more insulin to control their diabetes than non-smokers [22].

In view of the important role clinicians in primary care play in smoking cessation, the overall positive attitudes towards addressing tobacco dependence among older patients are encouraging. However, while the majority of clinicians believed that it was within their remit of responsibility as a healthcare professional to assist older smokers to address their tobacco dependence and a significant number of respondent medical staff reported having sufficient knowledge and skills to support cessation, non-medical staff reported feeling less confident in their ability. As nurses and healthcare assistants play an important role in primary care, particularly in terms of health promotion, screening, and monitoring activity, it is concerning that as many as $38.5 \%$ of non-medical staff reported lacking confidence in knowledge and skills required to be able to effectively encourage and support older patients in addressing their tobacco dependence.

The lack of association between training attendance and clinician attitudes and knowledge is remarkable. While, the survey did not assess the content or nature of smoking related training received by clinicians, it is likely that primary care staff would receive training in the promotion of smoking cessation as part of their pre-or post-registration education or professional development. To fully understand the impact of training on the attitudes and knowledge of clinicians further evidence is required on the type and content of training received by GP's, nurses, and healthcare assistants.

Previous research indicates that older people experience a number of psychological, physical, and social barriers to making a quit attempt and in accessing smoking cessation services [23, 24]. In addition, clinicians have been shown to believe that long term smokers are less willing to give up or are less receptive to brief advice [13].

Our study found that just under half of all respondents were unaware of the barriers to smoking cessation faced by older patients, and nearly $30 \%$ felt that it was the task of specialist staff to support older people in their cessation attempts. In addition, over one third of non-medical staff felt that "smoking is one of the few pleasures older people have". These attitudes are likely to impact on the clinicians' motivation to offer cessation support to older smokers, and the way they offer it. Furthermore, and similar to previous studies [25-27], clinicians reported a perceived lack of time during consultation with older patients to be able to provide smoking cessation advice and treatment. The benefits of quitting smoking in later life are well documented, as are the potential improvements to chronic, long-term and lifelimiting conditions and patients' quality of life. Despite this, our study found that nearly a quarter of respondents did not feel it was appropriate to discuss smoking cessation with patients with dementia, terminal illness, or mental disorder. Just over $3 \%$ reported a reluctance to discuss patients' smoking for fear of negative impacts on the therapeutic relationship, a finding that does not replicate the results of Coleman's study [25], which found that many of the 42 GP's interviewed cited that fear of harming the doctor-patient relationship was a barrier to discussing smoking with patients. While it is understandable that clinicians do not wish to add to patients health or social burdens or to stigmatise those who may be suffering from smoking related diseases, there is recent evidence to suggest that patients will accept life-style advice about behaviours associated with their illness [28]. Research conducted by Gritz et al. [29] highlighted the importance of clinical staff in promoting smoking cessation in cancer patients, suggesting that diagnosis and on-going clinical contacts provide opportunities for teachable moments and an improvement in condition or the effects of treatment [30].

\section{Conclusion}

Despite encouraging attitudes towards addressing tobacco use among older adults generally, our results across all staff groups show that opportunities for assisting older patients to address their tobacco dependence might currently be missed. There is a need to develop clinician capacity, knowledge and awareness related to smoking cessation in older people specifically, and to build confidence in seizing teachable moments, even or especially among those older people with chronic or terminal illnesses.

\section{Additional file}

Additional file 1: Primary care clinician survey.

\section{Abbreviations}

CCG: Clinical commissioning group; GP: General practice/general practitioner; HCA: Healthcare assistant; NHS: National health service; UK: United Kingdom.

\section{Competing interests}

The authors declare that they have no competing interests. 


\section{Authors' contributions}

ER and LH conceived the idea for this study. ER oversaw all aspects of the study and contributed to the development, authoring, and review of the paper. LH set-up the study, assisted in the distribution of the survey and collection of the data, undertook statistical analysis and contributed to the development, authoring, and review of the paper. GMW assisted in the distribution of the survey, entry of survey data, and in the development, authoring, and review of the paper. $\mathrm{RH}-\mathrm{M}$ contributed to the set-up of the study, distribution of the survey, collection of data, and review of the paper All authors read and

approved the final manuscript.

\section{Acknowledgements}

This work was supported by NHS Nottingham City CCG NIHR Research Capability Funding.

\section{Author details}

${ }^{1}$ Division of Epidemiology \& Public Health, The University Of Nottingham, Clinical Sciences Building, City Hospital Campus, Nottingham NG5 1PB, UK. ${ }^{2}$ Department of Medicine, CLAHRC EM, Institute of Mental Health, University of Nottingham, Nottingham, UK. ${ }^{3} \mathrm{NHS}$ Nottingham Clinical Commissioning Group, Nottingham, UK.

Received: 4 February 2015 Accepted: 30 July 2015

Published online: 06 August 2015

\section{References}

1. Cancer Research UK. Tobacco Statistics [http://www.cancerresearchuk.org/ cancer-info/cancerstats/causes/tobacco-statistics/\#By3]

2. Doll $\mathrm{R}$, Peto $\mathrm{R}$, Boreham J, Sutherland I. Mortality in relation to smoking: 50 years' observations on male British doctors. BMJ. 2004;328(7455):1519.

3. Geliert C, Schöttker B, Brenner H. Smoking and all-cause mortality in older people: systematic review and meta-analysis. Arch Intern Med. 2012;172:837-44

4. Gooneratne NS, Patel NP, Corcoran A. Chronic obstructive pulmonary disease diagnosis and management in older adults. J Am Geriatr Soc. 2010:58(6):1153-62.

5. Lester PE, Lyubarova R, Kirtani V, Macina LO, Kohen I. Smoking rates in dementia patients in the outpatient setting. Arch Gerontol Geriatr. 2011;52(3):281-3.

6. Anstey KJ, von Sanden C, Salim A, O'Kearney R. Smoking as a risk factor for dementia and cognitive decline: a meta-analysis of prospective studies. Am J Epidemiol. 2007;166(4):367-78.

7. Parry O, Thomson C, Fowkes FGR. Dependent behaviours and beliefs: a qualitative study of older long-term smokers with arterial disease. Addiction. 2001;96(9):1337-47.

8. Parry O, Thomson C, Fowkes G. Cultural context, older age and smoking in Scotland: qualitative interviews with older smokers with arterial disease. Health Promot Int. 2002;17(4):309-16.

9. Shankar A, McMunn A, Banks J, Steptoe A. Loneliness, social isolation, and behavioral and biological health indicators in older adults. Health Psychol. 2011;30(4):377

10. Donzé J, Ruffieux C, Cornuz J. Determinants of smoking and cessation in older women. Age Ageing. 2007;36(1):53-7.

11. Reid J. Tobacco and the over 65's: A needs assessment based on smokers' and carers' views. In. http://www.ashscotland.org.uk/media/3134/ NHS\%20Borders Inequalities_FinalProjectReport_Aug06.pdf: ASH Scotland, NHS Borders and Scottish Borders Council.; 2006: 1-57.

12. National Institute for Clinical Excellence. Smoking cessation services in primary care, pharmacies, local authorities and workplaces, particularly for manual working groups, pregnant women and hard to reach communities. 2008.

13. Tait RJ, Hulse GK, Waterreus A, Flicker L, Lautenschlager NT, Jamrozik K, et al. Effectiveness of a smoking cessation intervention in older adults. Addiction. 2007;102(1):148-55.

14. Runciman $\mathrm{P}$, Watson $\mathrm{H}$, Mclntosh J, Tolson D. Community nurses' health promotion work with older people. J Adv Nurs. 2006;55(1):46-57.

15. Kerr S, Watson H, Tolson D, Lough M, Brown M. An exploration of the knowledge, attitudes and practice of members of the primary care team in relation to smoking and smoking cessation in later life. Primary Health Care Research and Development. 2007;8(01):68-79.
16. Orleans CT, Rimer BK, Cristinzio S, Keintz MK, Fleisher L. A national survey of older smokers: treatment needs of a growing population. Health Psychol. 1991;10(5):343

17. Momen N, Hadfield P, Harrison K, Barclay S. Managing pain in advanced cancer: a survey of united kingdom general practitioners and community nurses. J Pain Symptom Manage. 2013:46(3):345-54.

18. Jawad M, Hamilton FL, Millett C, Albeyatti A, Ananthavarathan P. Knowledge and attitudes of waterpipe tobacco smoking among GPs in England. Br J Gen Pract. 2014;64(622):222-3.

19. Drennan V, Davis K. Trends over ten years in the primary care and community nurse workforce in England: Faculty of Health and Social Care Sciences. St. Georges: University of London and Kingston University; 2008.

20. McEwen A, West R. Smoking cessation activities by general practitioners and practice nurses. Tob Control. 2001;10(1):27-32

21. Scotland NHS. Primary Care Workforce Survey 2013: A survey of Scottish general practices and GP Out of Hours Services. Information Services Division. 2013.

22. Rimer B, Orleans C, Keintz M, Cristinzio S, Fleisher L. The older smoker. Status, challenges and opportunities for intervention. CHEST Journal. 1990;97(3):547-53

23. Whitson HE, Heflin MT, Burchett BM. Patterns and predictors of smoking cessation in an elderly cohort. J Am Geriatr Soc. 2006:54(3):466-71.

24. Appel DW, Aldrich TK. Smoking cessation in the elderly. Clin Geriatr Med. 2003;19(1):77-100

25. Coleman T, Murphy E, Cheater F. Factors influencing discussion of smoking between general practitioners and patients who smoke: a qualitative study. Br J Gen Pract. 2000;50(452):207-10.

26. Coleman T, Wilson A. Anti-smoking advice in general practice consultations: general practitioners' attitudes, reported practice and perceived problems. Br J Gen Pract. 1996;46(403):87-91.

27. Vogt F, Hall S, Marteau TM. General practitioners' and family physicians' negative beliefs and attitudes towards discussing smoking cessation with patients: a systematic review. Addiction. 2005;100(10):1423-31.

28. Williams K, Beeken R, Wardle J. Health behaviour advice to cancer patients: the perspective of social network members. Br J Cancer. 2013;108(4):831-5.

29. Gritz ER, Fingeret MC, Vidrine DJ, Lazev AB, Mehta NV, Reece GP. Successes and failures of the teachable moment. Cancer. 2006;106(1):17-27.

30. Rowland C, Danson S, Rowe R, Merrick H, Woll P, Hatton M, et al. Quality of life, support and smoking in advanced lung cancer patients: a qualitative study. BMJ supportive \& palliative care 2014:bmjspcare-2013-000589.

\section{Submit your next manuscript to BioMed Central and take full advantage of:}

- Convenient online submission

- Thorough peer review

- No space constraints or color figure charges

- Immediate publication on acceptance

- Inclusion in PubMed, CAS, Scopus and Google Scholar

- Research which is freely available for redistribution

Submit your manuscript at www.biomedcentral.com/submit
C Biomed Central 